\title{
Jumps in commodity markets
}

\section{Article}

Accepted Version

Creative Commons: Attribution-Noncommercial-No Derivative Works 4.0

Nguyen, D. B. B. and Prokopczuk, M. (2019) Jumps in commodity markets. Journal of Commodity Markets, 13. pp. 55-70. ISSN 2405-8513 doi: https://doi.org/10.1016/j.jcomm.2018.10.002 Available at https://centaur.reading.ac.uk/81482/

It is advisable to refer to the publisher's version if you intend to cite from the work. See Guidance on citing.

To link to this article DOI: http://dx.doi.org/10.1016/j.jcomm.2018.10.002

Publisher: Elsevier

All outputs in CentAUR are protected by Intellectual Property Rights law, including copyright law. Copyright and IPR is retained by the creators or other copyright holders. Terms and conditions for use of this material are defined in the End User Agreement.

\section{$\underline{\text { www.reading.ac.uk/centaur }}$}

\section{CentAUR}

Central Archive at the University of Reading

Reading's research outputs online 


\title{
Jumps in Commodity Markets*
}

\author{
Duc Binh Benno Nguyen ${ }^{\dagger} \quad$ Marcel Prokopczuk ${ }^{\dagger, \ddagger}$
}

September 28, 2018

\begin{abstract}
This paper investigates price jumps in commodity markets. We find that jumps are rare and extreme events but occur less frequently than in stock markets. Nonetheless, jump correlations across commodities can be high depending on the commodity sectors. Energy, metal and grains commodities show high jump correlations while jumps of meats and softs commodities are barely correlated. Looking at crossmarket correlations, we find that returns of commodities co-move with the stock market, while jumps can be diversified. Most commodities are strong hedges for U.S. Dollar returns but weak hedges for U.S. Dollar jumps. Most commodities act as both return and jump hedges for Treasury notes.
\end{abstract}

JEL classification: G10, G11, G13, Q02

Keywords: Commodities; Jump Risk; Tail Risk; Hedge

*Contact: prokopczuk@fmt.uni-hannover.de

${ }^{\dagger}$ School of Economics and Management, Leibniz University Hannover, Koenigsworther Platz 1, 30167 Hannover, Germany.

${ }^{\ddagger}$ ICMA Centre, Henley Business School, University of Reading, Reading, RG6 6BA, U.K. 


\section{Introduction}

This paper studies jumps in commodity markets and discusses the importance of jump diversification and contributes to the commodity markets literature by focusing on extreme returns rather than returns alone. There are many potential reasons why commodity prices might jumps. For example, energy prices react heavily to geopolitical events in the Middle East (as witnessed when Iraq invaded Kuwait) or Hurricanes in the Gulf of Mexico (such as Katrina in 2005). The prices for agricultural commodities might react heavily to adverse weather conditions, political announcements, or surprises in inventory announcements. Likewise, metal futures prices might react heavily to supply disruptions or international trade disputes. Therefore, consideration of jumps is of great importance when relying on cross-sectional and cross-market diversification for risk control. From a portfolio perspective, it is relevant whether jumps are highly correlated in the cross section and across markets or not, since high correlation would eliminate diversification benefits. The knowledge about specific commodities which show high/low jump correlation thus allows for a better portfolio allocation in times of market stress.

The contribution of our paper is threefold. First, we analyze jumps in 29 different commodity futures individually. Second, we analyze jump correlations across these markets. Third, we relate our results to other markets in order to draw conclusions on the potential of hedging jumps across markets.

Jumps are measured by the Barndorff-Nielsen \& Shephard (2006) (BNS) jump test statistic which is calculated for each commodity and calender month using daily futures returns' data. We investigate the correlation of jumps across commodities by computing the correlation coefficients of the jump measure. Our paper differs from the literature which relies mainly on parametric models and co-jumps and/or their probabilities while 
we investigate the presence of jumps non-parametrically and present evidence of jump correlations. Further, the literature considers mainly the co-movement of commodity prices given by the excess co-movement hypothesis introduced by Pindyck \& Rotemberg (1993). Generally, there is no empirical evidence of excess co-movement being found between various commodities using either cointegration techniques or multivariate GARCH models (Palaskas \& Varangis, 1991; Deb et al., 1996; Malliaris \& Urrutia, 1996). In our paper, we are interested in the co-movement of extreme events, rather than returns, but we investigate both to draw a complete picture.

We apply the jump detection test of Barndorff-Nielsen \& Shephard (2006) and correlation analysis to the daily futures return of 29 commodities over the period from January 1959 to December 2015. We show that some commodities' returns have more jumps than others with the percentage of jump months being as high as $20.5 \%$ for butter and as low as $0.1 \%$ for soybean meal. Jumps are very extreme and rare events where the jump size on average is more than 1000 times higher than the average raw returns but at the same time make up less than $1 \%$ of the raw returns. Nonetheless, jumps in commodity markets occur much less frequently than in the stock market, as found by Pukthuanthong \& Roll (2015). In a second step, we relate jumps of commodities to jumps in the U.S. stock market, the Treasury bond market and the currency market. Most commodities show relatively high co-movement with stock market returns while jumps are generally diversifiable. For the currency market, we find that almost all commodities are strong hedges for U.S. Dollar returns and weak hedges for U.S. Dollar jumps. Lastly. we find that most commodities serve as weak hedges for Treasury notes concerning both returns and jumps.

Our paper draws from three strands of literature. The first concentrates on jumps 
in the stock market and their potential cause by news events and their future effects on the equity risk premium. Rietz (1988) and Barro (2006) model tail risk and rare disasters in order to explain different puzzles of asset returns for the U.S. and 20 OECD countries, respectively. Lee \& Mykland (2008) find evidence for a relationship between jumps and news events in the U.S. equity market while the index jumps are associated with overall market news. Jiang \& Yao (2013) investigate the cross section of U.S. stock returns and find that small stocks, value stocks, illiquid stocks and past losers have higher jump returns than large stocks, growth stocks liquid stocks and past winners. The jumps are then related to future market returns. Pukthuanthong \& Roll (2015) investigate 82 different countries and their stock indices over more than four decades. They find that jumps are far less correlated than returns in terms of both magnitude and significance. Jumps are found to be generally uncorrelated and diversifiable.

Second, our paper is related to the commodity literature, especially studies investigating the dynamics and jumps in commodity markets. Chatrath \& Song (1999) find a negative relationship between the frequency of price jumps in the cash markets of agricultural commodities and both the number of speculative contracts and the number of speculators. Different commodities have different stochastic properties and hence should not be considered as a unified asset class, as shown by Brooks \& Prokopczuk (2013). They find that both returns and jumps are correlated within segments/sectors while generally independent across segments. Further, returns between commodities and the stock market are found to be low as well. For the co-movement of jumps they find mixed results between commodities and equities. Diewald et al. (2015) study jumps in the prices of energy futures and find that tail events exhibit seasonality. Their proposed model with seasonal jump intensity outperforms models with a constant jump intensity. The 
authors focus on the parametric modeling of jumps and (co-)jump intensities while we are interested in the detection of jumps and their correlation across commodity markets. Lombardi \& Ravazzolo (2016) examines the correlation between equity and commodity returns. Employing a time-varying Bayesian DCC model they conclude that the benefits from the inclusion of commodities into portfolios come alongside higher volatilities. Ohashi \& Okimoto (2016) investigate the co-movement of commodity prices for the period from 1983 to 2011, and show evidence for an increasing trend.

Lastly, the inclusion of jumps for the price modeling of commodities has gained some attention in the recent literature. Evidence of jumps and fat tails in commodity returns are documented by Deaton \& Laroque (1992) and Pindyck (2001), among others. The continuous time models for commoditiy derivatives pricing by Brennan \& Schwartz (1985), Gibson \& Schwartz (1990), Schwartz (1997) and Schwartz \& Smith (2000) have been extended to take into account jumps (Hilliard \& Reis, 1999; Deng, 2000; Manoliu \& Tompaidis, 2002; Casassus \& Collin-Dufresne, 2005). A few papers have focused on the detection and role of jumps non-parametrically in the sense that jumps are directly extracted from returns. Sévi (2015) examines the jumps in crude oil high-frequency prices and uses the methodology of Tauchen \& Zhou (2011). Chevallier \& Ielpo (2014) investigate the role of jumps at a daily frequency for 20 commodities and rely on the Laurent et al. (2011) methodology. They find that jumps in commodity markets are more frequent than in other asset classes, while there is a high discrepancy within the commodity markets concerning number, size and sign of the jumps. Prokopczuk et al. (2016) provide evidence of jumps in four energy markets and show that the modeling of jumps does not provide any significant improvement for volatility forecasting.

The rest of the paper is organized as follows. Section II describes our data sets and 
the methodology for our empirical analysis. Section III analyzes the jumps in commodity markets and investigates the impact of jumps on the returns. Section IV correlates jumps across markets and permits some conclusions on hedging. Section V concludes.

\section{Data and Methodology}

\section{A Methodology}

For our jump detection, we follow Pukthuanthong \& Roll (2015) and rely on the BarndorffNielsen \& Shephard (2006) (BNS) jump test. ${ }^{1}$ The following jump-diffusion process is assumed for the logarithmic price $p_{t}$ :

$$
d p_{t}=\mu_{t} d t+\sigma_{t} d W_{t}+\eta_{t} d N_{t}
$$

where $d p_{t}$ is the change in the log price, $\mu_{t}$ is the drift which is a locally bounded and predictable process of finite variance and $d t$ is an increment of time. $\sigma_{t}$ denotes the instantaneous volatility, which is a càdlàg process, while $W_{t}$ is a standard Brownian motion. The jump size is described by the random variable $\eta_{t}$ and $N_{t}$ is a Poisson jump process with intensity $\lambda_{t}$. The term $d N_{t}$ equals 1 if there is a jump during the increment $d t$, which occurs with probability $P\left(d N_{t}\right)=\lambda_{t} d t$, and 0 otherwise. The test relies on the decomposition of the quadratic variation $Q V_{t}$ of the process described above into a

\footnotetext{
${ }^{1}$ Alternative jump tests are compared by the authors, which were developed by Jiang \& Oomen (2008), Lee \& Mykland (2008) and Jacod \& Todorov (2009). Their simulations show that their proposed test is preferable compared to the others using different jump sizes and frequencies.
} 
continuous and discontinuous component, i.e.

$$
Q V_{t}=\underbrace{\int_{t-1}^{t} \sigma_{s}^{2} d s}_{\text {continuous }}+\underbrace{\sum_{t-1 \leq \pi_{i} \leq t} \eta_{\pi_{i}}^{2}}_{\text {discontinuous }}
$$

where $\pi_{i}$ refer to the times of corresponding jumps (with $i=1,2, \ldots, N_{t}$ ). The quadratic variation and its components are estimated at a monthly frequency from daily returns' data where the return in month $t$ on day $k$ is defined as:

$$
r_{t, k}=p_{t, k}-p_{t, k-1}
$$

Typically, a month consists of $K_{t}=21$ business days, i.e. $k=1, \ldots, K_{t}$. The squared variation is defined as the average of the sum of squared daily returns:

$$
S_{t}=\frac{1}{K_{t}} \sum_{k=1}^{K_{t}} r_{t, k}^{2}
$$

For high sampling frequencies, the squared variation is a consistent estimator for the quadratic variation. The continuous component of the quadratic variation is estimated by the bipower variation:

$$
B_{t}=\frac{1}{K_{t}-1} \sum_{k=2}^{K_{t}}\left|r_{t, k}\right|\left|r_{t, k-1}\right|
$$


The BNS jump statistic relies on the discontinuous component described by the difference of $S_{t}$ and $B_{t}$, and is given by:

$$
\begin{aligned}
B N S_{t} & =\frac{(\pi / 2) B_{t}-S_{t}}{\sqrt{\left(\left(\pi^{2} / 4\right)+\pi-5\right)(\pi / 2)^{2} Q_{t}}} \\
Q_{t} & =\frac{1}{K_{t}-3} \sum_{k=4}^{K_{t}}\left|r_{t, k}\right|\left|r_{t, k-1}\right|\left|r_{t, k-2}\right|\left|r_{t, k-3}\right|
\end{aligned}
$$

where $Q_{t}$ describes the quarticity of the jump-diffusion process. For months with smooth returns the squared variation is relatively small while jumps are magnified by the square leading to smaller values of the test statistic. The null hypothesis of no jumps is asymptotically unit normal and typically rejected for small values of $B N S_{t}$.

For our empirical analysis we follow Pukthuanthong \& Roll (2015) and compute the monthly time series of $B N S_{i, t}$ for every asset $i$ under consideration. We then compute Pearson correlation coefficients for pairwise time series of $B N S_{i, t}$.

\section{B Data}

We obtain commodity futures data from the Commodity Research Bureau (CRB) for commodities traded at the four major North American Exchanges (NYMEX, NYBOT, CBOT and CME). We include the same commodities as in Gorton \& Rouwenhorst (2006) and Gorton et al. (2013). We exclude Propane and Pork Bellies since these were delisted in 2009 and 2011, respectively. We also exclude the commodity futures traded on the London Metals Exchange (LME), resulting into 29 commodities. We divide these into five sectors: Energy, metals, grains, meats and softs. An overview of the commodities is reported in Table 1 including the start of available observations and exchanges. The earliest date with available daily observation starts in 1959 and varies across commodities. 
Unlike stocks, commodity futures have expiration dates. For the computation of a continuous return series we follow Diewald et al. (2015) and differentiate between normal returns and roll-over returns. More specifically, we compute the futures returns as follows:

$$
r_{t+1}^{\text {normal }}=\log \frac{F_{t+1}^{(1)}}{F_{t}^{(1)}} \quad \quad r_{t+1}^{\text {roll }}=\log \frac{F_{t+1}^{(1)}}{F_{t}^{(2)}}
$$

where $r_{t+1}^{\text {roll }}$ denotes the futures return at time $t+1$ on a business day immediately after the expiration day and $r_{t+1}^{\text {normal }}$ denotes the futures return on any other business day. $F_{t}^{(1)}$ and $F_{t}^{(2)}$ refer to the first nearby contract and the second nearby contract at time $t$, respectively. ${ }^{2}$ This method ensures that every return could have been realized, i.e. is based on one contract only. We rely on daily futures returns in order to estimate monthly BNS statistics. ${ }^{3}$

Table 2 shows the summary statistics of daily returns for the 29 commodities. The daily mean return lies between $0.00 \%$ and $0.01 \%$ for all commodities while skewness and kurtosis vary a lot across commodities. Most commodity returns are left skewed while kurtosis is as low as 4.89 for cocao and as high as 302.12 for cotton. The generally large kurtosis, and the large minimum and maximum indicate the presence of extreme events which we examine below.

\footnotetext{
${ }^{2}$ We also consider alternative rolling dates such as the end of the first or second month prior to the delivery month in order to avoid irregular price behavior (Szymanowska et al., 2014). This is important since we are interested in jumps in particular which may appear more frequently in illiquid close-to-maturity futures contracts. Our main conclusions on the hedging and safe haven performance of commodities for various asset classes remain unchanged. The corresponding tables are available upon request.

${ }^{3}$ The returns present excess returns or futures risk premiums (Gorton \& Rouwenhorst, 2006; Gorton et al., 2013; Bhardwaj et al., 2015).
} 


\section{Commodity Jumps}

\section{A Individual Jumps}

We first analyze jumps in individual commodity markets. Figure 1 illustrates the percentage of significant jumps (at the $5 \%$ significance level) for the individual commodities. The commodities butter and milk exhibit by far the most jumps, where $20.5 \%$ and $7.2 \%$ of the months include jumps. Both futures were introduced rather recently, so the sample period is relatively short and the markets are young. The precious metals gold and silver show also relatively many jumps with a percentage of $2.6 \%$ and $1.9 \%$, respectively. Soybean meal and live cattle have the least jumps with a proportion of only $0.1 \%$ and $0.2 \%$, respectively. These findings are also reflected in the summary statistics reported in Table 3, Panel A. Butter and milk exhibit the highest absolute average BNS statistic with values of -2.67 and -0.62 , respectively. Unleaded gas, silver and gold have slightly lower averages with values between -0.36 and -0.34 .

Panel B of Table 3 reports the summary statistics for the BNS jump statistic for all commodities in the first row, and averages for different sectors in rows two to six. The mean varies between -0.71 and -0.08 which is much lower than the one computed by Pukthuanthong \& Roll (2015) for international stock returns (-6.799). The meats sector shows the lowest average BNS statistic while the grain sector shows the largest. Again, the magnitude is much smaller than in international stock returns. For comparison, Pukthuanthong \& Roll (2015) find that 12 of the 82 investigated countries exhibit more than $30 \%$ jumps. The skewness is negative for all sectors and the kurtosis shows remarkably large values for all sectors as well. While the average BNS statistics indicate that jumps are much less frequent than in international stock returns, the higher moments show ev- 
idence of extreme downside movements of the BNS statistic. This is supported by the maximum values, which are all lower than 0.50 , and the minimum values dramatically lower than the $5 \%$ significance value of $-1.96 .^{4}$

Table 4 compares the average return and jump size for the 29 commodities. We report the average return of positive and negative jump returns and the proportion to the total observations per commodity. The table shows that jumps are rare and extreme events. Butter futures experience most jumps where $0.62 \%$ of the daily returns are jumps. Also, both positive and negative jumps have on average much higher magnitudes than the raw returns. Across all commodities (positive and negative) jumps are substantially bigger than the raw returns.

\section{B Jumps and Liquidity}

Jiang et al. (2011) show that liquidity shocks and jumps are related in the U.S. Treasurybond market. They find that liquidity shocks have predictive power for jumps while macroeconomic announcements have limited predictive power. Jiang \& Yao (2013) show that illiquid stocks exhibit higher jump returns than liquid stocks and that jumps are one main driver of the cross-sectional return predictability. Motivated by these findings which shows a clear relationship between jumps and liquidity in the stock and bond markets, we investigate whether this is true for the commodity markets as well.

Following Amihud (2002), we measure the illiquidity of a commodity futures as the

\footnotetext{
${ }^{4}$ Our results somewhat differ from those of Chevallier \& Ielpo (2014), who find that commodities generally show more jumps than the stock market. But the authors rely on a different jump test and consider the detection of realized jump days while we are interested in whether a certain month includes jumps following Pukthuanthong \& Roll (2015). Also their investigation period is much shorter, including the period from 1995 until 2012, compared to our sample from 1959 until 2015.
} 
average ratio of absolute returns and dollar volume:

$$
\text { Illiquidity }_{t}=\frac{\left|r_{t}\right|}{\text { volume }_{t}}
$$

Marshall et al. (2012) compare various measures of liquidity based on both high-frequency and low-frequency data for 24 commodities and show that the Amihud measure has the best performance in the sense that it shows the largest correlation with liquidity benchmarks. We compute the monthly illiquidity as the average over that month following Marshall et al. (2012) and Marshall et al. (2013).

For each commodity we obtain the daily dollar volume, volume , of the closest to maturity contract by multiplying the volume with the price, which are both obtained from CRB. We conduct our analysis for the period from January 2001 until December 2015. Our choice of the subsample is restricted by the volume data availability from CRB. We test the relationship between jumps and liquidity by estimating the following cross-sectional regression in each month:

$$
B N S_{i, t}=\alpha_{t}+\beta_{t} \text { Illiquidity }_{i, t}+\epsilon_{t}
$$

where $\alpha_{t}$ and $\beta_{t}$ are the intercept and slope coefficients in month $t$ and $\epsilon_{t}$ is the error term. The time-series average of the coefficients and the t-statistics in square brackets are estimated as follows:

$$
\bar{\alpha}_{t}=\frac{-0.1995}{[-16.2991]} \quad \bar{\beta}_{t}=\frac{-0.0268}{[-1.7824]}
$$

Hence, there is some evidence for a negative relationship between the illiquidity and the 
jumps of a commodity (statistically significant at the $10 \%$ level). Higher illiquidity leads to a lower BNS jump test statistic, i.e. a higher jump intensity. We therefore provide evidence that the negative relationship between illiquidity and jumps documented by Jiang et al. (2011) and Jiang \& Yao (2013) for the stock and bond market is also present in commodity futures markets.

\section{Jump Correlations}

The results so far show that jumps are more relevant in certain commodity sectors than in others, even though being in general less frequent than in equity markets. We next investigate the correlation of jumps across commodities. For each of the 406 commodity pairs, we calculate both individual BNS statistics for each month and correlate them across all months. Table 5 reports the results. The mean correlation coefficient of 0.03 for the jumps across all pairs is relatively low and much lower than the mean correlation of raw returns as reported in the second row. Further, only $11.82 \%$ of the commodity pairs show significantly correlated jumps compared to the $50.49 \%$ of significantly correlated return pairs. One should note that since we define co-jumps as jumps occurring in the same months, our results are an upper limit for the question whether jumps occur on the same day.

The relatively weak co-movement of jumps across commodities is also shown by the most influential calender months. A month is defined as influential for which the demeaned product of returns is the absolute largest over all available months. Table 6 reports the percentage of commodity pairs for which a certain month was the most influential in terms of jumps (Panel A) and returns (Panel B). For the returns there are three grossly dominant months (July 1973, March 1980 and October 2008), where the 
Financial Crisis in October 2008 is the most influential $(22.22 \%$ of the pairs). For the jumps, no month is even influential for $10 \%$ of the pairs. Further, the most influential months for returns do not appear in the list of influential months for jumps. Figure 2 provides a graphical illustration of the influential months. As one can see, the largest peaks for both jumps and returns occur at different points in time.

So far, the results suggest that commodity price jumps not only happen infrequently but also at different times across commodity markets. Table 7 presents exceptions from this general finding. We report those commodity pairs that show highly correlated jump months. We list all pairs for which the t-statistic for the BNS statistic is at least 3.0. As immediately evident, the energy sector shows high co-movement of jumps, filling five of the first six rows. Other pairs with significant jump correlations are inter alia soybean commodities (soybeans, soybean meal and soybean oil) and precious metals (gold, platinum and silver). This motivates us to repeat the previous exercise for individual sectors since related commodities (commodities of the same sector) seem to show higher jump correlations than unrelated commodities.

Table 8 reports the average correlation coefficient of two sectors and the related percentage of significant coefficients in square brackets below. The correlation of jumps within certain individual sectors and their statistical significance are much higher than the average across all commodities (0.03). The energy, metals and grains sector show relatively high correlations between 0.07 and 0.25 with $20.00 \%$ to remarkably $53.33 \%$ of the pairs showing significant correlations while meats and softs commodities show no jump co-movements within the sectors. Intuitively, the correlation of jumps across sectors are rather low, with values between 0.00 and 0.03 . Return correlations are again much higher for both pairs within and across sectors. All pairs within the metals and grains 
sector show significant return correlations with means of 0.51 and 0.43 , respectively. The highest return correlations are found between the metals and energy or grains sectors.

Overall, diversification of extreme movements in a commodity-based portfolio is thus most effective when using commodities of the meats and softs sector or commodities of different sectors, while diversification is less effective within energy, metals or grains sectors.

\section{Impact of Jumps on Returns}

Since the correlation of raw returns is found to be high while the correlation of jumps shows low to no correlation, returns without jumps should show even larger correlations. To analyze this, we purge the raw returns of jumps and investigate those. Similar to the procedure for detecting jumps, we first compute the BNS statistic for each commodity and month. If there is no significant jump at the $10 \%$ significance level the monthly return is calculated from the month of daily returns. If there is a significant jump we repeatedly remove the highest absolute return and recalculate the BNS statistic until it is no longer significant. The remaining returns are then used to calculate the monthly return.

Table 9 reports the summary statistics of the jump-purged returns in comparison with raw returns and jumps. The difference of average correlations between raw and purged returns is essentially zero while the percentage of significant correlation coefficients barely decreases from $50.49 \%$ to $50.25 \%$. The same is true when looking at correlations within and across market segments. Table 10 shows the average time-series correlation coefficient and the percentage of significant correlations for purged returns. The results are very similar to the ones for the returns (including jumps). This supports our previous findings 
that jumps happen rarely and not at the same time across commodities and thus barely influence the return correlations.

\section{Jump Correlations across Asset Classes}

In Section III we examined the correlation of jumps across various commodities and commodity sectors. In the next step, we investigate the relationship to further markets, which can give an insight into diversifying jumps across markets. This is particularly interesting since some commodities are rumored to be good hedges/safe havens for stock, exchange rate or bond markets. Our analysis allows us to name commodities which are actually good and bad hedges with respect to large price fluctuations. We consider the overall commodity market proxied by the Goldman Sachs Commodity Index, the stock market proxied by the S\&P 500 E-Mini futures and S\&P 500 futures and the U.S. exchange rate market proxied by the U.S. Dollar Index futures. Further, we investigate the bond market and include futures on Treasury notes of various maturities. The results are reported in Table 11 in Panel A, B, C and D for the commodity, stock and exchange markets, respectively. Results for the bonds' futures are reported in Table 12. The relevant CRB symbols are GI, ES, SP, DX, TU, FV and TY. All contracts are traded on CME except for the Dollar Index futures, which is traded on the Intercontinental Exchange (ICE). All futures data are obtained from CRB. We differentiate between strong and weak hedges following Baur \& McDermott (2010). If one asset is uncorrelated with another asset, we refer to it as a weak hedge. If it is negatively correlated with another asset, we refer to it as a strong hedge. We are interested in both the "normal" and jump hedge performance of the commodities and base our conclusions on return and jump correlations, respectively. 


\section{A Commodities and the Goldman Sachs Index}

The Goldman Sachs Commodity Index (GSCI) was introduced in 1991 and forms a weighted average of 24 different commodity futures. Nearly all of the constituents are covered by the 29 futures considered in our analysis where crude oil and heating oil have the highest weights of $23.04 \%$ and $20.43 \%$, respectively. ${ }^{5}$ Hence, it is intuitive that the energy sector including crude oil and heating oil has the highest correlations with the GSCI. Panel A of Table 11 shows that this is true for both jumps and returns where the correlations vary between 0.02 and 0.54 and 0.38 and 0.88 , respectively. The coefficient is statistically significant for 5 out of the 6 energy commodities when looking at jumps and all when looking at returns. The return correlation of metals and the GSCI are lower but still considerably high, varying between 0.28 and 0.45 and being all statistically significant. The return correlation of meats commodities is the lowest. Turning next to the jump correlations, only the precious metals (and energy commodities) show (statistically significant) correlation coefficients higher than 0.10 . The remaining commodities show low and insignificant jump correlation. Jumps for many meats and softs commodities are even negatively correlated to GSCI jumps. All in all, the returns of most commodities show high and significant return correlations while only energy and precious metals show moderate to high jump correlations with the index.

\section{B Commodities and the Stock Market}

Commodities have been the target for diversifying stock portfolios since they are seemingly uncorrelated with the stock market (Gorton \& Rouwenhorst, 2006). But several studies provide evidence of increasing return correlation, especially after the financializa-

\footnotetext{
${ }^{5}$ Source Thomson Reuters Tick History (updated January 2016).
} 
tion of commodity markets (Tang \& Xiong, 2012; Ohashi \& Okimoto, 2016). Further, investors seek hedging or safe haven assets, especially since recent years have been marked by times of financial distress like the burst of the dot-com bubble, the Lehman default, the great recession followed by the European debt crisis and the Chinese stock market crash.

We look at the jump correlations between commodity and stock markets which indicate the hedging properties in times of market tumult. The S\&P 500 index is the natural benchmark/proxy for the stock market but we also include the S\&P 500 E-Mini futures since the liquidity is much higher for the latter: the results for both are qualitatively similar so we focus our discussion on the latter. ${ }^{6}$ Intuitively, both return and jump correlations of commodities with the stock market are significantly lower than with the GSCI. Only lean hogs show a positive (0.16) and statistically significant jump correlation with the S\&P while the jumps of remaining commodities are uncorrelated or even negatively correlated (but statistically insignificant). Energy, metals and meats commodities in particular show negative jump correlations.

For the returns, the results are mixed. Lean hogs show the lowest return correlation with the S\&P with a coefficient of -0.04 . For other commodities the coefficient is as high as 0.44 (copper). Also, more than half of the commodities show a positive and statistically significant correlation with the returns of the stock market. The findings in the literature are mixed. Silvennoinen \& Thorp (2013) argue that the correlation was rather low starting in the 1990s and increased significantly after major crises while Chong \& Miffre (2010) find decreasing co-movement over time.

Even though the returns of commodities somewhat co-move with the stock market

\footnotetext{
${ }^{6}$ We show that using either of the two proxies, we find qualitatively similar results for the commodities even though the data availability for the S\&P 500 E-Mini futures starts a bit later (September 9th, 1995) compared to the S\&P 500 index (April 21st 1982).
} 
returns, jumps of both markets are generally uncorrelated or negatively correlated, which is good news for investors. Extreme commodity and stock market movements can hence be diversified by adding (weak) hedge assets from the market. This is consistent with Silvennoinen \& Thorp (2013), who investigate 24 individual commodities and show that commodity-stock correlations are low during market turbulences.

\section{Commodities and Dollar Investment}

Next, we consider the currency market in the U.S. relying on the U.S. Dollar Index futures. The U.S. Dollar Index was introduced in 1973 and represents the value of U.S. Dollars by taking into account the exchange rate with six other currencies: Euro, Japanese yen, British pound, Canadian dollar, Swedish krona and Swiss franc. ${ }^{7}$ Commodities and the dollar seem to be natural hedges for each other since they are negatively correlated. This makes sense because the dollar price is the benchmark for most commodities and commodities are traded globally. Akram (2009) finds that lower commodity prices are followed by a fall of the dollar value. Reboredo et al. (2014) focus their study on the commodity crude oil but also find a negative dependence to the dollar.

Panel D in Table 11 confirms this intuition, which is consistent with the literature and shows that 28 of the 29 commodities possess negative return correlations with the U.S. Dollar Index from which 19 are statistically significant. The coefficients vary from -0.34 for gold to 0.01 for lumber. Jumps, on the other hand, show relatively low and mixed correlation coefficients. About half show negative correlations while none of the coefficients is higher than 0.09 in absolute terms and only one is statistically significant (Coffee). Commodities are overall strong hedges for the returns of the U.S. Dollar Index

\footnotetext{
${ }^{7}$ For the time before 1999, the Belgian, Dutch, French, German and Italian currencies were used instead of the Euro.
} 
and at the same time weak hedges for jumps as well.

\section{Commodities and Bonds}

Lastly, we investigate the relationship with fixed income securities. More specifically, we consider futures on Treasury notes with two, five and ten years' maturity. The results presented in Table 12 are generally similar for all Treasury notes. We find that the returns of most commodities are either uncorrelated or negatively correlated with Treasury note returns of all maturities. There are two exceptions: natural gas and gold returns are positively correlated with the returns of the Treasury notes which is statistically significant. Six, eight and six of the commodities are strong hedges for the two, five and ten years' Treasury notes, respectively, while the remaining ones are weak hedges.

The results for the jump correlations are mixed. While five and two of the commodities show positive and statistically significant jump correlation with the two and five years' Treasury notes, all commodities are either weak or strong jump hedges for the ten years' Treasury note.

Hence, most commodities are suitable return and jump hedges for Treasury notes even though there are exceptions. Our results concerning the return correlations are in accordance with the literature. Gorton \& Rouwenhorst (2006) show that commodity futures returns and bond returns are generally negatively correlated. One of the exceptions we find is gold. Baur \& Lucey (2010) show that gold serves as a safe haven for bonds in the U.S. but not as a hedge. 


\section{Conclusion}

To have a diversified cross-market portfolio allocation, it is important to know to which extent the jumps of commodities, stocks and other assets are correlated. If they are uncorrelated across markets one can protect oneself against sharp price movements through diversification.

We investigate the jump correlation within the commodity market and the U.S. stock, currency and bond markets. We do so by correlating the monthly estimates of the BNS test statistic. While jumps occur much less frequently than in stock markets, some commodities exhibit relatively many jumps, e.g. butter and milk. Moreover, while returns show moderate and statistically significant correlations, jump correlations differ a lot across commodities. Energy, metal and grains commodities in particular show high jump co-movements while jumps of meats and softs commodities are uncorrelated. The same is true for the returns, where energy, metals and grains commodities exhibit much higher return correlations of 0.43 to 0.51 , compared to 0.08 to 0.20 of the remaining two sectors.

The hedging abilities of commodities also varies. Correlation coefficients for commodity returns and stock market returns vary from -0.04 to 0.44 , while jumps are uncorrelated or negatively correlated. Commodity returns and U.S. Dollar returns are (except for lumber) negatively correlated while jumps are uncorrelated or negatively correlated. Commodities are generally hedging assets against Treasury note returns and jumps, even though there are several exceptions. In summary, most commodities are strong hedges for dollar and bond returns while only some are able to hedge for S\&P 500 returns. At the same time jumps in the stock, currency and bond markets are generally diversifiable by adding commodities to the basket. 


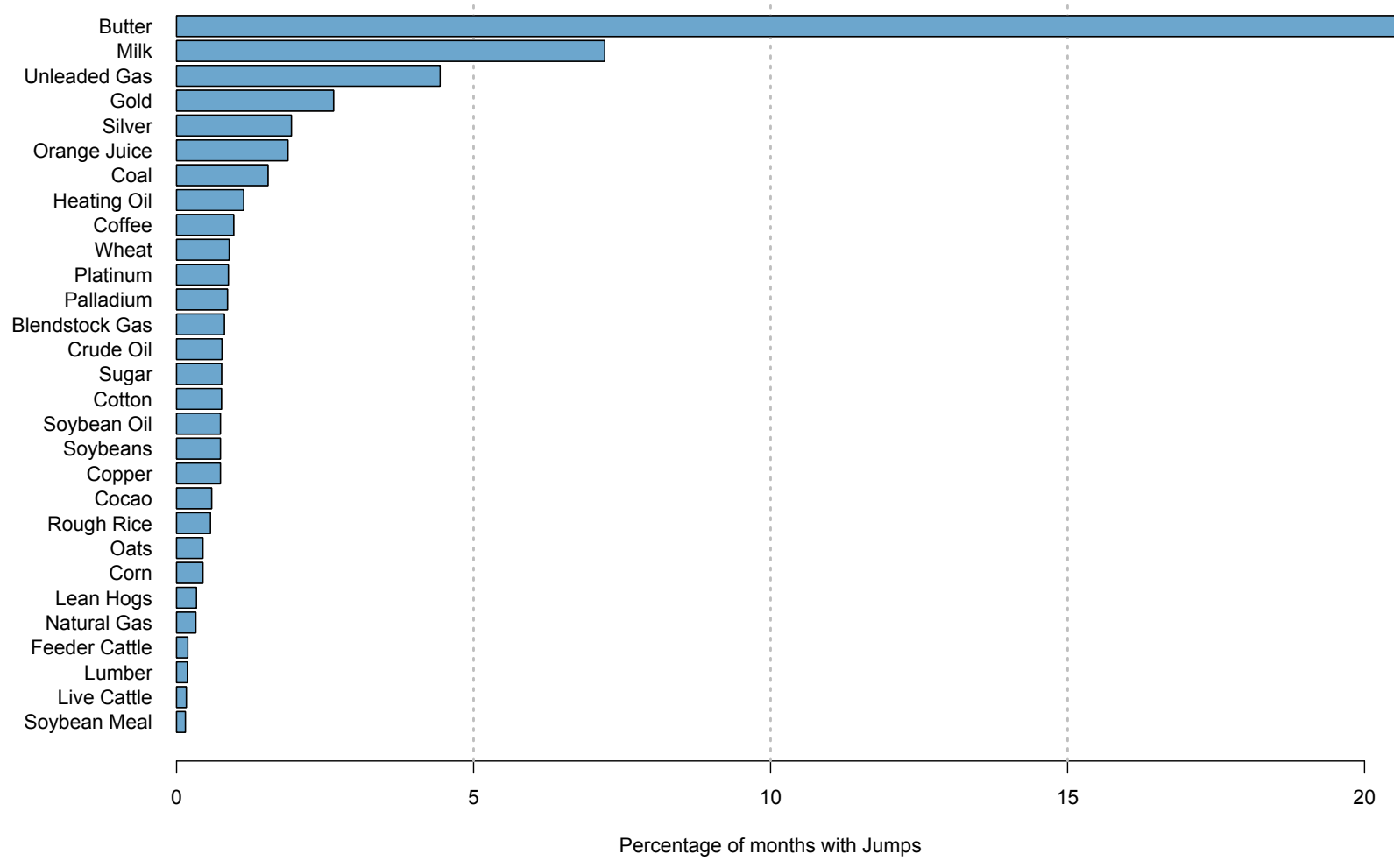

Figure 1: Percentage Months with Significant Jumps

This figure presents the percentage of months that contain jumps which are significant at the $5 \%$ level. Jumps are measured by the test statistic of Barndorff-Nielsen \& Shephard (2006) for the 29 commodities using daily observations within each calender month. 

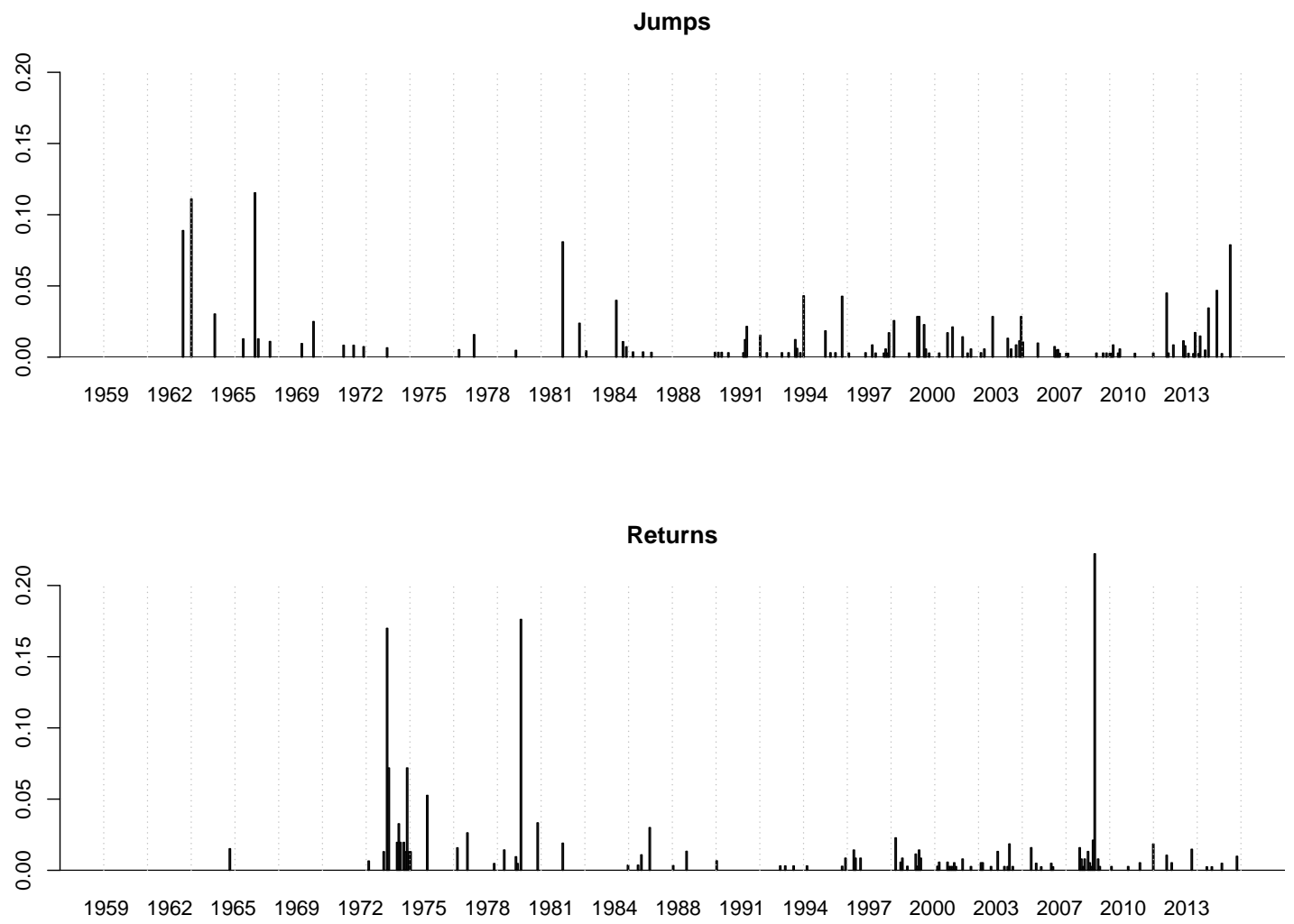

Figure 2: Influential Months

This figure presents the most influential months on the horizontal axis and the percentage of commodity pairs for which it is most influential on the vertical axis. We report the most influential months for jumps (top panel) and returns (bottom panel). 
Table 1: Overview of Selected Commodities

This table presents an overview of the commodities we investigate in this paper. We report the sector, the commodity, the symbol, the exchange and the period, for which data is available. Source: http://www.crbtrader.com/marketdata/. For copper, we use Old Copper (CU) for the period until December 1988 and High Grade Copper (HG) starting in January 1989. For hogs, we use Live Hogs $(L G)$ for the period until December 1996 and Lean Hogs (LH) starting in February 1997.

\begin{tabular}{|c|c|c|c|c|}
\hline Sector & Commodity & Symbol & Exchange & Sample Period \\
\hline \multirow[t]{7}{*}{ Energy } & Heating Oil & $\mathrm{HO}$ & NYMEX/COMEX & $1978 / 11-2015 / 12$ \\
\hline & Crude Oil & CL & NYMEX/COMEX & $1983 / 03-2015 / 12$ \\
\hline & Unleaded Gas & $\mathrm{HU}$ & NYMEX/COMEX & $1984 / 12-2006 / 12$ \\
\hline & & & & $2013 / 09-2015 / 12$ \\
\hline & Natural Gas & NG & NYMEX/COMEX & $1990 / 04-2015 / 12$ \\
\hline & Coal & QL & NYMEX/COMEX & $2001 / 07-2015 / 12$ \\
\hline & Blendstock Gas & $\mathrm{RB}$ & NYMEX/COMEX & $1984 / 12-2015 / 12$ \\
\hline \multirow[t]{5}{*}{ Metals } & Copper & $\mathrm{HG}$ & NYMEX/COMEX & $1959 / 07-2015 / 12$ \\
\hline & Silver & SI & NYMEX/COMEX & $1963 / 06-2015 / 12$ \\
\hline & Platinum & PL & NYMEX/COMEX & $1968 / 03-2015 / 12$ \\
\hline & Gold & $\mathrm{GC}$ & NYMEX/COMEX & $1974 / 12-2015 / 12$ \\
\hline & Palladium & PA & NYMEX/COMEX & $1977 / 01-2015 / 12$ \\
\hline \multirow[t]{7}{*}{ Grains } & Wheat & W- & $\mathrm{CBOT}$ & $1959 / 07-2015 / 12$ \\
\hline & Corn & $\mathrm{C}-$ & CBOT & $1959 / 07-2015 / 12$ \\
\hline & Soybeans & S- & $\mathrm{CBOT}$ & $1959 / 07-2015 / 12$ \\
\hline & Soybean Oil & $\mathrm{BO}$ & $\mathrm{CBOT}$ & $1959 / 07-2015 / 12$ \\
\hline & Soybean Meal & SM & $\mathrm{CBOT}$ & $1959 / 07-2015 / 12$ \\
\hline & Oats & O- & $\mathrm{CBOT}$ & $1959 / 07-2015 / 12$ \\
\hline & Rough Rice & $\mathrm{RR}$ & CBOT & $1986 / 08-2015 / 12$ \\
\hline \multirow[t]{5}{*}{ Meats } & Live Cattle & $\mathrm{LC}$ & CME & $1964 / 11-2015 / 12$ \\
\hline & Lean Hogs & LH & $\mathrm{CME}$ & $1966 / 02-2015 / 12$ \\
\hline & Feeder Cattle & $\mathrm{FC}$ & $\mathrm{CME}$ & $1971 / 11-2015 / 12$ \\
\hline & Milk & $\mathrm{DE}$ & $\mathrm{CME}$ & $1996 / 01-2015 / 12$ \\
\hline & Butter & $\mathrm{BA}$ & $\mathrm{CME}$ & $2005 / 09-2015 / 12$ \\
\hline \multirow[t]{6}{*}{ Softs } & Cotton & $\mathrm{CT}$ & $\mathrm{ICE}$ & $1959 / 07-2015 / 12$ \\
\hline & Cocao & $\mathrm{CC}$ & ICE & $1959 / 07-2015 / 12$ \\
\hline & Sugar & $\mathrm{SB}$ & $\mathrm{ICE}$ & $1961 / 01-2015 / 12$ \\
\hline & Orange Juice & $\mathrm{JO}$ & $\mathrm{ICE}$ & $1967 / 02-2015 / 12$ \\
\hline & Lumber & LB & $\mathrm{CME}$ & $1969 / 01-2015 / 12$ \\
\hline & Coffee & $\mathrm{KC}$ & $\mathrm{ICE}$ & $1972 / 08-2015 / 12$ \\
\hline
\end{tabular}


Table 2: Summary Statistics of Daily Returns

This table presents the summary statistics of daily returns (in percent). We report the number of daily observations $N$, time-series averages, medians, standard deviations, skewness and kurtosis of the returns and the maximum and the minimum returns.

\begin{tabular}{|c|c|c|c|c|c|c|c|c|c|}
\hline & & $N$ & Mean & Median & Std. dev. & Skewness & Kurtosis & Maximum & Minimum \\
\hline \multirow[t]{6}{*}{ Energy } & Heating Oil & 9319 & 0.01 & 0.03 & 2.25 & -1.42 & 19.48 & 13.99 & -39.09 \\
\hline & Crude Oil & 8221 & 0.00 & 0.03 & 2.38 & -0.79 & 15.16 & 16.41 & -40.05 \\
\hline & Unleaded Gas & 6127 & 0.01 & 0.05 & 2.66 & 1.56 & 70.64 & 63.29 & -37.12 \\
\hline & Natural Gas & 6460 & 0.01 & 0.00 & 3.58 & 0.17 & 14.71 & 44.70 & -46.75 \\
\hline & Coal & 3630 & 0.00 & 0.00 & 1.52 & -0.11 & 10.43 & 12.61 & -11.08 \\
\hline & Blendstock Gas & 7798 & 0.01 & 0.06 & 2.53 & -0.56 & 18.42 & 35.33 & -37.12 \\
\hline \multirow[t]{5}{*}{ Metals } & Copper & 14159 & 0.01 & 0.02 & 1.79 & -1.11 & 16.87 & 17.07 & -33.53 \\
\hline & Silver & 13167 & 0.02 & 0.00 & 1.93 & -0.48 & 13.54 & 28.69 & -24.57 \\
\hline & Platinum & 11996 & 0.01 & 0.04 & 1.80 & -2.30 & 95.25 & 31.55 & -57.04 \\
\hline & Gold & 10301 & 0.02 & 0.00 & 1.24 & -0.11 & 6.95 & 9.74 & -9.91 \\
\hline & Palladium & 9787 & 0.02 & 0.04 & 2.08 & -0.27 & 5.89 & 15.25 & -18.87 \\
\hline \multirow[t]{7}{*}{ Grains } & Wheat & 14232 & 0.01 & 0.00 & 1.74 & -1.37 & 28.56 & 23.30 & -31.41 \\
\hline & Corn & 14232 & 0.01 & 0.00 & 1.58 & -1.08 & 56.78 & 35.47 & -36.49 \\
\hline & Soybeans & 14232 & 0.01 & 0.05 & 1.57 & -0.82 & 14.76 & 20.32 & -23.41 \\
\hline & Soybean Oil & 14229 & 0.01 & 0.00 & 1.73 & -0.37 & 9.40 & 17.65 & -21.76 \\
\hline & Soybean Meal & 14230 & 0.01 & 0.00 & 1.95 & -0.39 & 12.57 & 22.87 & -20.55 \\
\hline & Oats & 14235 & 0.01 & 0.00 & 2.02 & -0.98 & 13.24 & 19.79 & -25.46 \\
\hline & Rough Rice & 7402 & 0.01 & 0.00 & 1.74 & 0.43 & 32.76 & 32.38 & -24.45 \\
\hline \multirow[t]{5}{*}{ Meats } & Live Cattle & 12873 & 0.01 & 0.04 & 1.18 & -0.63 & 11.03 & 13.30 & -10.38 \\
\hline & Lean Hogs & 12558 & 0.00 & 0.04 & 2.10 & -0.55 & 29.40 & 28.56 & -27.79 \\
\hline & Feeder Cattle & 11113 & 0.01 & 0.00 & 1.04 & -0.22 & 9.76 & 10.30 & -12.49 \\
\hline & Milk & 5025 & 0.00 & 0.00 & 1.92 & -2.99 & 97.51 & 27.93 & -35.13 \\
\hline & Butter & 2591 & 0.01 & 0.00 & 1.63 & -3.81 & 107.92 & 17.32 & -31.40 \\
\hline \multirow[t]{6}{*}{ Softs } & Cotton & 14155 & 0.00 & 0.00 & 1.75 & -7.25 & 302.12 & 16.69 & -78.41 \\
\hline & Cocao & 14120 & 0.01 & 0.00 & 1.95 & -0.20 & 4.89 & 16.61 & -21.78 \\
\hline & Sugar & 13733 & 0.01 & 0.00 & 2.78 & 0.43 & 11.50 & 35.36 & -29.42 \\
\hline & Orange Juice & 12248 & 0.01 & 0.03 & 2.11 & -0.09 & 35.33 & 39.67 & -39.97 \\
\hline & Lumber & 11658 & 0.01 & 0.00 & 2.11 & 0.55 & 9.80 & 19.71 & -20.44 \\
\hline & Coffee & 10856 & 0.01 & 0.00 & 2.37 & -0.06 & 9.66 & 23.77 & -24.42 \\
\hline
\end{tabular}


Table 3: Summary Statistics of the Jump Measure

This table presents the summary statistics of the jumps measured by the test statistic of Barndorff-Nielsen \& Shephard (2006). We report the number of monthly observations $N$, time-series averages, medians, standard deviations, the average t-statistic $t$, the mean absolute deviation $M A D$, the skewness and kurtosis and the maximum and minimum values for individual commodities across months in Panel A. Panel B reports the corresponding statistics for all commodities or sectors.

\begin{tabular}{|c|c|c|c|c|c|c|c|c|c|c|}
\hline & $N$ & Mean & Median & Std. dev. & $t$ & MAD & Skewness & Kurtosis & Maximum & Minimum \\
\hline \multicolumn{11}{|c|}{ Panel A: Individual Commodities } \\
\hline Heating Oil & 443.00 & -0.13 & -0.02 & 0.45 & -6.03 & 0.28 & -3.87 & 28.22 & 0.44 & -4.43 \\
\hline Crude Oil & 393.00 & -0.15 & -0.04 & 0.43 & -6.98 & 0.30 & -2.22 & 10.17 & 0.35 & -2.71 \\
\hline Unleaded Gas & 293.00 & -0.34 & -0.10 & 0.81 & -7.09 & 0.48 & -4.27 & 30.00 & 0.37 & -6.84 \\
\hline Natural Gas & 309.00 & -0.14 & -0.04 & 0.38 & -6.38 & 0.28 & -1.56 & 6.46 & 0.40 & -2.13 \\
\hline Coal & 130.00 & -0.29 & 0.00 & 1.57 & -2.08 & 0.53 & -9.44 & 99.77 & 0.41 & -16.96 \\
\hline Blendstock Gas & 373.00 & -0.12 & -0.01 & 0.39 & -6.07 & 0.28 & -2.26 & 11.45 & 0.37 & -2.72 \\
\hline Copper & 678.00 & -0.15 & -0.03 & 0.45 & -8.81 & 0.31 & -2.46 & 12.36 & 0.42 & -3.40 \\
\hline Silver & 621.00 & -0.36 & -0.10 & 2.01 & -4.47 & 0.55 & -15.45 & 273.62 & 0.45 & -39.53 \\
\hline Platinum & 574.00 & -0.15 & -0.04 & 0.45 & -7.76 & 0.30 & -2.91 & 17.37 & 0.40 & -3.97 \\
\hline Gold & 492.00 & -0.34 & -0.18 & 0.66 & -11.31 & 0.42 & -4.31 & 38.07 & 0.33 & -7.60 \\
\hline Palladium & 467.00 & -0.13 & -0.01 & 0.47 & -5.98 & 0.30 & -3.63 & 27.45 & 0.40 & -4.85 \\
\hline Wheat & 678.00 & -0.07 & 0.02 & 0.53 & -3.63 & 0.26 & -10.97 & 194.50 & 0.41 & -10.07 \\
\hline Corn & 678.00 & -0.05 & 0.04 & 0.37 & -3.61 & 0.26 & -2.77 & 17.27 & 0.44 & -3.43 \\
\hline Soybeans & 678.00 & -0.11 & -0.00 & 0.42 & -7.06 & 0.28 & -3.26 & 22.35 & 0.40 & -4.04 \\
\hline Soybean Oil & 678.00 & -0.09 & 0.00 & 0.38 & -6.09 & 0.26 & -2.56 & 12.96 & 0.46 & -2.61 \\
\hline Soybean Meal & 678.00 & -0.11 & -0.01 & 0.37 & -7.84 & 0.26 & -2.38 & 14.52 & 0.40 & -3.48 \\
\hline Oats & 678.00 & -0.05 & 0.04 & 0.41 & -3.46 & 0.25 & -5.35 & 60.32 & 0.43 & -5.63 \\
\hline Rough Rice & 351.00 & -0.06 & 0.03 & 0.36 & -3.32 & 0.26 & -2.20 & 10.75 & 0.41 & -2.25 \\
\hline Live Cattle & 613.00 & -0.07 & 0.01 & 0.34 & -5.02 & 0.25 & -2.09 & 12.96 & 0.45 & -3.04 \\
\hline Lean Hogs & 598.00 & -0.09 & 0.01 & 0.35 & -6.04 & 0.26 & -1.95 & 9.00 & 0.40 & -2.35 \\
\hline Feeder Cattle & 529.00 & -0.09 & 0.00 & 0.38 & -5.71 & 0.28 & -1.74 & 7.31 & 0.45 & -2.37 \\
\hline Milk & 222.00 & -0.62 & -0.04 & 2.26 & -4.11 & 0.99 & -5.92 & 43.49 & 0.42 & -20.01 \\
\hline Butter & 78.00 & -2.67 & -0.14 & 8.72 & -2.70 & 4.09 & -5.07 & 31.51 & 0.39 & -62.01 \\
\hline Cotton & 662.00 & -0.15 & -0.05 & 0.46 & -8.62 & 0.32 & -2.33 & 11.25 & 0.40 & -3.37 \\
\hline Cocao & 678.00 & -0.09 & 0.02 & 0.46 & -5.24 & 0.28 & -5.63 & 65.92 & 0.42 & -6.59 \\
\hline Sugar & 660.00 & -0.13 & -0.01 & 0.50 & -6.86 & 0.31 & -4.85 & 46.98 & 0.47 & -6.35 \\
\hline Orange Juice & 587.00 & -0.26 & -0.09 & 0.73 & -8.49 & 0.40 & -6.32 & 64.43 & 0.39 & -9.53 \\
\hline Lumber & 555.00 & -0.04 & 0.09 & 1.08 & -0.82 & 0.28 & -20.63 & 463.63 & 0.43 & -24.35 \\
\hline Coffee & 520.00 & -0.18 & -0.05 & 0.48 & -8.74 & 0.32 & -2.99 & 18.88 & 0.40 & -4.46 \\
\hline \multicolumn{11}{|c|}{ Panel B: Sectors } \\
\hline All & 513.59 & -0.25 & -0.02 & 0.92 & -5.87 & 0.47 & -4.86 & 54.07 & 0.47 & -62.01 \\
\hline Energy & 323.50 & -0.19 & -0.03 & 0.67 & -5.77 & 0.36 & -3.91 & 27.68 & 0.44 & -16.96 \\
\hline Metals & 566.40 & -0.22 & -0.07 & 0.81 & -7.67 & 0.37 & -5.74 & 70.52 & 0.45 & -39.53 \\
\hline Grains & 631.29 & -0.08 & 0.02 & 0.41 & -5.00 & 0.26 & -4.20 & 44.38 & 0.46 & -10.07 \\
\hline Meats & 408.00 & -0.71 & -0.03 & 2.41 & -4.71 & 1.17 & -3.32 & 17.59 & 0.45 & -62.01 \\
\hline Softs & 628.40 & -0.14 & -0.01 & 0.65 & -6.01 & 0.32 & -7.95 & 127.44 & 0.47 & -24.35 \\
\hline
\end{tabular}


Table 4: Summary Statistics of Daily Returns and Jumps

This table presents the summary statistics of daily returns (in percent). We report the number of daily observations $N$, the average daily return, Mean, the average positive (negative) jump returns, Pos. Jumps (Neg. Jumps) and their proportion.

\begin{tabular}{|c|c|c|c|c|c|c|c|}
\hline & & $N$ & Mean & Pos. Jumps & $N_{\text {Pos. }} / N$ & Neg. Jumps & $N_{\text {Neg. }} / N$ \\
\hline \multirow[t]{6}{*}{ Energy } & Heating Oil & 9319 & 0.03 & & 0.00 & -6.42 & 0.05 \\
\hline & Crude Oil & 8221 & 0.01 & & 0.00 & -8.64 & 0.04 \\
\hline & Unleaded Gas & 6127 & 0.02 & 9.50 & 0.11 & -11.23 & 0.10 \\
\hline & Natural Gas & 6460 & -0.07 & 8.69 & 0.02 & & 0.00 \\
\hline & Coal & 3630 & -0.02 & 3.84 & 0.06 & & 0.00 \\
\hline & Blendstock Gas & 7798 & 0.05 & 6.11 & 0.03 & -6.66 & 0.01 \\
\hline \multirow[t]{5}{*}{ Metals } & Copper & 14159 & 0.03 & 5.43 & 0.03 & -2.75 & 0.01 \\
\hline & Silver & 13167 & 0.01 & 5.31 & 0.05 & -4.37 & 0.05 \\
\hline & Platinum & 11996 & 0.01 & 7.84 & 0.02 & -3.77 & 0.03 \\
\hline & Gold & 10301 & 0.01 & 3.49 & 0.06 & -3.97 & 0.08 \\
\hline & Palladium & 9787 & 0.02 & 7.30 & 0.04 & & 0.00 \\
\hline \multirow{7}{*}{ Grains } & Wheat & 14232 & -0.01 & 14.40 & 0.01 & -5.35 & 0.03 \\
\hline & Corn & 14232 & -0.01 & & 0.00 & -5.81 & 0.02 \\
\hline & Soybeans & 14232 & 0.02 & 3.85 & 0.03 & -4.39 & 0.01 \\
\hline & Soybean Oil & 14229 & 0.02 & 8.04 & 0.01 & -4.97 & 0.03 \\
\hline & Soybean Meal & 14230 & 0.05 & 3.98 & 0.01 & -5.47 & 0.01 \\
\hline & Oats & 14235 & 0.01 & 9.35 & 0.01 & -14.45 & 0.01 \\
\hline & Rough Rice & 7402 & -0.01 & 6.89 & 0.04 & & 0.00 \\
\hline \multirow[t]{5}{*}{ Meats } & Live Cattle & 12873 & 0.04 & 4.06 & 0.01 & & 0.00 \\
\hline & Lean Hogs & 12552 & 0.04 & 27.31 & 0.01 & -16.02 & 0.02 \\
\hline & Feeder Cattle & 11113 & 0.02 & & 0.00 & -1.67 & 0.01 \\
\hline & Milk & 5024 & 0.02 & 3.34 & 0.24 & -5.31 & 0.14 \\
\hline & Butter & 2591 & -0.02 & 5.76 & 0.39 & -4.27 & 0.23 \\
\hline \multirow[t]{6}{*}{ Softs } & Cotton & 14155 & -0.01 & 2.15 & 0.01 & -5.24 & 0.03 \\
\hline & Cocao & 14120 & 0.00 & 9.25 & 0.01 & -9.58 & 0.02 \\
\hline & Sugar & 13733 & -0.04 & 5.95 & 0.01 & -14.36 & 0.03 \\
\hline & Orange Juice & 12248 & 0.02 & 16.62 & 0.07 & -6.08 & 0.02 \\
\hline & Lumber & 11658 & -0.04 & 15.13 & 0.01 & -94.05 & 0.01 \\
\hline & Coffee & 10856 & 0.00 & 5.07 & 0.03 & -8.23 & 0.03 \\
\hline
\end{tabular}


Table 5: Correlation of Jump Measure and Returns across Commodities

This table presents the summary statistics of the correlation of jumps measured by the test statistic of Barndorff-Nielsen \& Shephard (2006) in the first row and of returns in the second row. There are 29 commodities and 406 pairs. The statistics below are computed across all 406 pairs. We report time-series averages, medians, standard deviations, the average t-statistic, $t$, the average mean absolute deviation, $M A D$, the skewness and kurtosis and the maximum and minimum values across all commodities and months. The last column reports the percentage of all correlation coefficients for which the t-statistic is higher than 2.0 .

\begin{tabular}{llccccccccc}
\hline & Mean & Median & Std. dev. & $t$ & MAD & Skewness & Kurtosis & Maximum & Minimum & $t>2$ \\
\hline Jumps & 0.03 & 0.02 & 0.09 & 0.66 & 0.06 & 2.91 & 15.38 & 0.76 & -0.20 & $11.82 \%$ \\
Returns & 0.13 & 0.10 & 0.16 & 3.13 & 0.11 & 1.97 & 5.16 & 0.89 & -0.19 & $50.49 \%$ \\
\hline \hline
\end{tabular}


Table 6: Influential Months for Correlation of Returns and Jumps

This table presents the most influential months for the jump and return correlations in Panel A and B, respectively. The jumps are measured by the test statistic of BarndorffNielsen \& Shephard (2006). The single calender month which contributes the most to the correlation of jump measures between a pair of commodities is defined as "influential". We only include months with at least 100 available pairs and which are most influential to at least $2 \%$ of the observations.

\begin{tabular}{lc} 
Panel A: Jumps \\
\hline Year-Month & Most influential \% \\
\hline $1969-11$ & 2.50 \\
$1982-04$ & 8.10 \\
$1983-02$ & 2.38 \\
$1984-12$ & 3.99 \\
$1991-06$ & 2.15 \\
$1994-04$ & 4.31 \\
$1996-03$ & 4.27 \\
$1998-10$ & 2.56 \\
$1999-12$ & 2.85 \\
$2000-01$ & 2.85 \\
$2000-04$ & 2.28 \\
$2001-09$ & 2.12 \\
$2003-09$ & 2.85 \\
$2005-02$ & 2.85 \\
$2012-05$ & 4.50 \\
$2014-06$ & 3.45 \\
$2014-11$ & 4.68 \\
$2015-07$ & 7.88 \\
\hline \hline
\end{tabular}

Panel B: Returns

\begin{tabular}{lc}
\hline Year-Month & Most influential \% \\
\hline $1973-07$ & 16.99 \\
$1973-08$ & 7.19 \\
$1974-02$ & 3.27 \\
$1974-07$ & 7.19 \\
$1975-07$ & 5.26 \\
$1980-03$ & 17.62 \\
$1981-01$ & 3.33 \\
$2008-10$ & 22.22
\end{tabular}

22.22 
Table 7: Pairs of Commodities with Largest Jump Correlation

This table presents the commodity pairs with the highest jump correlation. Jumps are measured by the test statistic of Barndorff-Nielsen \& Shephard (2006). The pairs of commodities listed here exhibit jump measure correlations with t-statistics higher than 3.0. The last column reports the related correlation coefficient.

\begin{tabular}{llcc}
\hline & & t-statistic & Correlation \\
\hline Heating Oil & Coal & 13.16 & 0.76 \\
Heating Oil & Crude Oil & 13.10 & 0.55 \\
Soybeans & Soybean Meal & 12.65 & 0.44 \\
Unleaded Gas & Blendstock Gas & 11.79 & 0.57 \\
Crude Oil & Blendstock Gas & 7.80 & 0.38 \\
Heating Oil & Blendstock Gas & 6.96 & 0.34 \\
Soybeans & Soybean Oil & 6.93 & 0.26 \\
Crude Oil & Coal & 6.83 & 0.52 \\
Silver & Gold & 6.56 & 0.28 \\
Crude Oil & Unleaded Gas & 5.64 & 0.31 \\
Soybean Oil & Soybean Meal & 5.28 & 0.20 \\
Live Cattle & Feeder Cattle & 4.78 & 0.20 \\
Corn & Soybeans & 3.99 & 0.15 \\
Heating Oil & Unleaded Gas & 3.84 & 0.22 \\
Natural Gas & Copper & 3.68 & 0.21 \\
Soybeans & Feeder Cattle & 3.64 & 0.16 \\
Heating Oil & Cotton & 3.55 & 0.17 \\
Platinum & Gold & 3.55 & 0.16 \\
Wheat & Soybean Meal & 3.54 & 0.13 \\
Soybean Meal & Feeder Cattle & 3.42 & 0.15 \\
\hline \hline
\end{tabular}


Table 8: Correlation of Jump Measure across Commodity Sectors

This table presents the summary statistics of the correlation of jumps measured by the test statistic of Barndorff-Nielsen \& Shephard (2006) in Panel A and of raw returns in Panel B. There are 29 commodities divided into 5 sectors. The statistics below are computed within and across sectors. We report the average time-series correlation coefficient and the percentage of all correlation coefficients for which the t-statistic is higher than $2.0 \mathrm{in}$ square brackets below.

\begin{tabular}{|c|c|c|c|c|c|}
\hline & Energy & Metals & Grains & Meats & Softs \\
\hline \multicolumn{6}{|c|}{ Panel A: Jumps } \\
\hline \multirow[t]{2}{*}{ Energy } & 0.25 & 0.01 & 0.01 & 0.00 & 0.01 \\
\hline & {$[53.33 \%]$} & {$[10.00 \%]$} & {$[9.52 \%]$} & {$[10.00 \%]$} & [8.33\%] \\
\hline \multirow[t]{2}{*}{ Metals } & & 0.07 & 0.01 & 0.01 & 0.01 \\
\hline & & {$[20.00 \%]$} & {$[0.00 \%]$} & {$[4.00 \%]$} & {$[0.00 \%]$} \\
\hline \multirow[t]{2}{*}{ Grains } & & & 0.10 & 0.02 & 0.02 \\
\hline & & & {$[52.38 \%]$} & {$[20.00 \%]$} & [4.76\%] \\
\hline \multirow[t]{2}{*}{ Meats } & & & & 0.09 & 0.03 \\
\hline & & & & {$[10.00 \%]$} & [6.67\%] \\
\hline \multirow[t]{2}{*}{ Softs } & & & & & 0.02 \\
\hline & & & & & {$[6.67 \%]$} \\
\hline \multicolumn{6}{|c|}{ Panel B: Returns } \\
\hline \multirow[t]{2}{*}{ Energy } & 0.48 & 0.14 & 0.08 & 0.01 & 0.05 \\
\hline & [93.33\%] & [63.33\%] & [30.95\%] & {$[13.33 \%]$} & [19.44\%] \\
\hline \multirow[t]{2}{*}{ Metals } & & 0.51 & 0.14 & 0.02 & 0.13 \\
\hline & & {$[100.00 \%]$} & {$[85.71 \%]$} & {$[28.00 \%]$} & {$[80.00 \%]$} \\
\hline \multirow[t]{2}{*}{ Grains } & & & 0.43 & 0.06 & 0.13 \\
\hline & & & {$[100.00 \%]$} & {$[34.29 \%]$} & [69.05\%] \\
\hline \multirow[t]{2}{*}{ Meats } & & & & 0.20 & 0.03 \\
\hline & & & & {$[40.00 \%]$} & {$[10.00 \%]$} \\
\hline \multirow[t]{2}{*}{ Softs } & & & & & 0.08 \\
\hline & & & & & {$[53.33 \%]$} \\
\hline
\end{tabular}


Table 9: Correlation of Returns Purged of Jumps across Commodities

This table presents the summary statistics of the correlation of jump-purged returns. Jumps are measured by the test statistic of Barndorff-Nielsen \& Shephard (2006). There are 29 commodities and 406 pairs. The statistics below are computed across all 406 pairs. We report time-series averages, standard deviations, medians, the average t-statistic $t$, the average mean absolute deviation $M A D$, the skewness and kurtosis and the maximum and minimum values across all commodities and months. The last column reports the percentage of all correlation coefficients for which the t-statistic is higher than 2.0.

\begin{tabular}{llccccccccc}
\hline & Mean & Median & Std. dev. & $t$ & MAD & Skewness & Kurtosis & Maximum & Minimum & $t>2$ \\
\hline Jumps & 0.03 & 0.02 & 0.09 & 0.66 & 0.06 & 2.91 & 15.38 & 0.76 & -0.20 & $11.82 \%$ \\
Returns & 0.13 & 0.10 & 0.16 & 3.13 & 0.11 & 1.97 & 5.16 & 0.89 & -0.19 & $50.49 \%$ \\
Purged Returns & 0.13 & 0.10 & 0.16 & 3.15 & 0.11 & 1.92 & 4.99 & 0.89 & -0.20 & $50.25 \%$ \\
\hline \hline
\end{tabular}


Table 10: Correlation of Jump Measure across Commodity Sectors

This table presents the summary statistics of the correlation of jumps measured by the test statistic of Barndorff-Nielsen \& Shephard (2006) in Panel A, of raw returns in Panel $\mathrm{B}$ and of returns purged by jumps in Panel C. There are 29 commodities divided into 5 sectors. The statistics below are computed within and across sectors. We report the average time-series correlation coefficient and the percentage of all correlation coefficients for which the t-statistic is higher than 2.0 in square brackets below.

\begin{tabular}{|c|c|c|c|c|c|}
\hline \multirow{2}{*}{\multicolumn{6}{|c|}{$\begin{array}{r}\text { Energy } \\
\text { Panel A: Jumps }\end{array}$}} \\
\hline & & & & & \\
\hline \multirow[t]{2}{*}{ Energy } & 0.25 & 0.01 & 0.01 & 0.00 & 0.01 \\
\hline & {$[53.33 \%]$} & {$[10.00 \%]$} & {$[9.52 \%]$} & {$[10.00 \%]$} & {$[8.33 \%]$} \\
\hline \multirow[t]{2}{*}{ Metals } & & 0.07 & 0.01 & 0.01 & 0.01 \\
\hline & & {$[20.00 \%]$} & {$[0.00 \%]$} & [4.00\%] & {$[0.00 \%]$} \\
\hline \multirow[t]{2}{*}{ Grains } & & & 0.10 & 0.02 & 0.02 \\
\hline & & & {$[52.38 \%]$} & {$[20.00 \%]$} & {$[4.76 \%]$} \\
\hline \multirow[t]{2}{*}{ Meats } & & & & 0.09 & 0.03 \\
\hline & & & & {$[10.00 \%]$} & {$[6.67 \%]$} \\
\hline \multirow[t]{2}{*}{ Softs } & & & & & 0.02 \\
\hline & & & & & {$[6.67 \%]$} \\
\hline \multicolumn{6}{|c|}{ Panel B: Returns } \\
\hline \multirow[t]{2}{*}{ Energy } & 0.48 & 0.14 & 0.08 & 0.01 & 0.05 \\
\hline & {$[93.33 \%]$} & {$[63.33 \%]$} & {$[30.95 \%]$} & {$[13.33 \%]$} & [19.44\%] \\
\hline \multirow[t]{2}{*}{ Metals } & & 0.51 & 0.14 & 0.02 & 0.13 \\
\hline & & {$[100.00 \%]$} & {$[85.71 \%]$} & {$[28.00 \%]$} & {$[80.00 \%]$} \\
\hline \multirow[t]{2}{*}{ Grains } & & & 0.43 & 0.06 & 0.13 \\
\hline & & & {$[100.00 \%]$} & {$[34.29 \%]$} & [69.05\%] \\
\hline \multirow[t]{2}{*}{ Meats } & & & & 0.20 & 0.03 \\
\hline & & & & {$[40.00 \%]$} & {$[10.00 \%]$} \\
\hline \multirow{2}{*}{\multicolumn{2}{|c|}{ Softs }} & & & & 0.08 \\
\hline & & & & & {$[53.33 \%]$} \\
\hline \multicolumn{6}{|c|}{ Panel C: Purged Returns } \\
\hline \multirow[t]{2}{*}{ Energy } & 0.48 & 0.15 & 0.08 & 0.02 & 0.05 \\
\hline & {$[93.33 \%]$} & {$[66.67 \%]$} & {$[33.33 \%]$} & {$[10.00 \%]$} & [19.44\%] \\
\hline \multirow[t]{2}{*}{ Metals } & & 0.51 & 0.14 & 0.01 & 0.13 \\
\hline & & {$[100.00 \%]$} & {$[82.86 \%]$} & {$[24.00 \%]$} & {$[76.67 \%]$} \\
\hline \multirow[t]{2}{*}{ Grains } & & & 0.43 & 0.06 & 0.13 \\
\hline & & & {$[100.00 \%]$} & {$[34.29 \%]$} & [69.05\%] \\
\hline \multirow[t]{2}{*}{ Meats } & & & & 0.21 & 0.03 \\
\hline & & & & {$[40.00 \%]$} & [13.33\%] \\
\hline \multirow[t]{2}{*}{ Softs } & & & & & 0.08 \\
\hline & & & & & {$[53.33 \%]$} \\
\hline
\end{tabular}


Table 11: Jump Correlation with Other Asset Classes

This table presents the jump and returns correlation of commodities with selected indices. We include the Goldman Sachs Commodity Index (Goldman), S\&P 500 E-mini futures (E-Mini), S\&P 500 futures $(S \& P$ ) and Dollar futures (Dollar) in Panel A, B, C and D, respectively. Jumps are measured by the test statistic of Barndorff-Nielsen \& Shephard (2006). T-statistics are reported in square brackets.

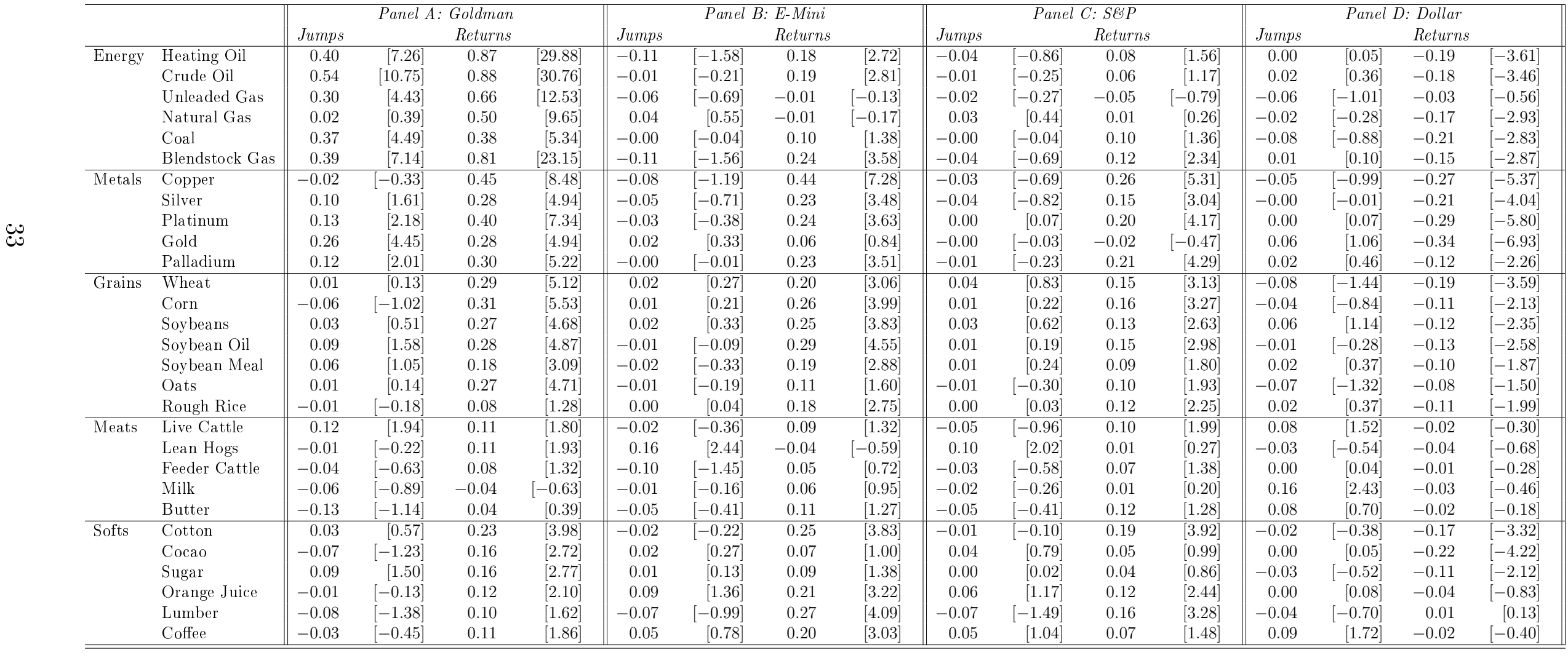


Table 12: Jump Correlation with Bond Futures

This table presents the jump and returns correlation of commodities with selected bond futures. We include the 2 (TU), 5 (FV) and 10 (TY) years treasury notes in Panel A, B, and C, respectively. Jumps are measured by the test statistic of Barndorff-Nielsen \& Shephard (2006). T-statistics are reported in square brackets.

\begin{tabular}{|c|c|c|c|c|c|c|c|c|c|c|c|c|c|}
\hline & \multicolumn{4}{|c|}{ Panel A: 2 Years' T-Note } & \multicolumn{4}{|c|}{ Panel B: 5 Years' T-Note } & \multicolumn{4}{|c|}{ Panel C: 10 Years' T-Note } \\
\hline & & \multicolumn{2}{|c|}{ Jumps } & \multicolumn{2}{|c|}{ Returns } & \multicolumn{2}{|c|}{ Jumps } & \multicolumn{2}{|c|}{ Returns } & \multicolumn{2}{|c|}{ Jumps } & \multicolumn{2}{|c|}{ Returns } \\
\hline \multirow[t]{6}{*}{ Energy } & Heating Oil & 0.01 & {$[0.22]$} & -0.10 & {$[-1.73]$} & -0.05 & {$[-0.93]$} & -0.11 & {$[-2.05]$} & -0.06 & {$[-1.22]$} & -0.11 & {$[-2.23]$} \\
\hline & Crude Oil & 0.13 & {$[2.26]$} & -0.09 & {$[-1.48]$} & 0.04 & {$[0.74]$} & -0.13 & {$[-2.37]$} & -0.05 & {$[-1.01]$} & -0.17 & {$[-3.46]$} \\
\hline & Unleaded Gas & 0.46 & {$[7.78]$} & -0.04 & {$[-0.63]$} & 0.07 & {$[1.03]$} & -0.08 & {$[-1.20]$} & -0.00 & {$[-0.04]$} & -0.13 & {$[-2.16]$} \\
\hline & Natural Gas & -0.05 & {$[-0.83]$} & 0.12 & {$[2.16]$} & -0.04 & {$[-0.77]$} & 0.14 & {$[2.46]$} & -0.01 & {$[-0.14]$} & 0.10 & {$[1.84]$} \\
\hline & Coal & -0.07 & {$[-0.75]$} & 0.04 & {$[0.49]$} & -0.03 & {$[-0.29]$} & -0.00 & {$[-0.01]$} & -0.01 & {$[-0.09]$} & 0.02 & {$[0.22]$} \\
\hline & Blendstock Gas & 0.09 & {$[1.65]$} & -0.08 & {$[-1.45]$} & -0.01 & {$[-0.11]$} & -0.12 & {$[-2.27]$} & 0.01 & {$[0.13]$} & -0.15 & {$[-2.95]$} \\
\hline \multirow[t]{5}{*}{ Metals } & Copper & -0.02 & {$[-0.37]$} & -0.12 & {$[-2.11]$} & 0.07 & {$[1.26]$} & -0.13 & {$[-2.45]$} & 0.01 & {$[0.23]$} & -0.09 & {$[-1.90]$} \\
\hline & Silver & -0.06 & {$[-1.09]$} & -0.02 & {$[-0.37]$} & 0.00 & {$[0.09]$} & -0.00 & {$[-0.07]$} & -0.05 & {$[-0.93]$} & -0.05 & {$[-1.01]$} \\
\hline & Platinum & 0.05 & {$[0.84]$} & -0.04 & {$[-0.76]$} & 0.05 & {$[0.87]$} & -0.02 & {$[-0.43]$} & 0.00 & {$[0.01]$} & -0.02 & {$[-0.36]$} \\
\hline & Gold & 0.01 & {$[0.26]$} & 0.14 & {$[2.48]$} & -0.01 & {$[-0.26]$} & 0.16 & {$[3.00]$} & -0.02 & {$[-0.36]$} & 0.10 & {$[1.91]$} \\
\hline & Palladium & 0.01 & {$[0.23]$} & -0.09 & {$[-1.54]$} & -0.03 & {$[-0.59]$} & -0.06 & {$[-1.15]$} & -0.00 & {$[-0.03]$} & -0.07 & {$[-1.32]$} \\
\hline \multirow[t]{7}{*}{ Grains } & Wheat & 0.02 & {$[0.31]$} & 0.08 & {$[1.41]$} & 0.01 & {$[0.20]$} & 0.09 & [1.59] & 0.01 & {$[0.24]$} & 0.04 & {$[0.76]$} \\
\hline & Corn & -0.01 & {$[-0.10]$} & -0.04 & {$[-0.69]$} & -0.01 & {$[-0.13]$} & 0.02 & {$[0.31]$} & -0.05 & {$[-1.01]$} & -0.04 & {$[-0.77]$} \\
\hline & Soybeans & 0.05 & {$[0.85]$} & 0.01 & {$[0.25]$} & 0.10 & {$[1.88]$} & -0.00 & {$[-0.01]$} & -0.06 & {$[-1.14]$} & -0.06 & {$[-1.30]$} \\
\hline & Soybean Oil & 0.14 & {$[2.53]$} & -0.02 & {$[-0.32]$} & -0.05 & {$[-0.99]$} & -0.03 & {$[-0.48]$} & -0.10 & {$[-1.95]$} & -0.05 & {$[-1.02]$} \\
\hline & Soybean Meal & 0.01 & {$[0.12]$} & 0.01 & {$[0.17]$} & 0.13 & [2.30] & -0.01 & {$[-0.20]$} & -0.04 & {$[-0.83]$} & -0.04 & {$[-0.71]$} \\
\hline & Oats & 0.01 & {$[0.23]$} & 0.04 & {$[0.70]$} & 0.04 & {$[0.76]$} & 0.02 & {$[0.30]$} & 0.02 & {$[0.36]$} & -0.02 & {$[-0.38]$} \\
\hline & Rough Rice & 0.11 & {$[1.93]$} & 0.01 & {$[0.09]$} & 0.04 & {$[0.64]$} & 0.04 & {$[0.78]$} & 0.07 & {$[1.27]$} & 0.05 & {$[0.84]$} \\
\hline \multirow[t]{5}{*}{ Meats } & Live Cattle & -0.08 & {$[-1.35]$} & -0.11 & {$[-1.99]$} & -0.05 & {$[-0.93]$} & -0.12 & {$[-2.25]$} & -0.08 & {$[-1.69]$} & -0.07 & {$[-1.38]$} \\
\hline & Lean Hogs & -0.08 & {$[-1.31]$} & 0.06 & {$[0.97]$} & 0.01 & {$[0.23]$} & 0.06 & [1.13] & 0.06 & {$[1.15]$} & 0.06 & {$[1.25]$} \\
\hline & Feeder Cattle & 0.03 & {$[0.52]$} & -0.10 & {$[-1.72]$} & 0.02 & {$[0.30]$} & -0.10 & {$[-1.84]$} & 0.02 & {$[0.46]$} & -0.04 & {$[-0.88]$} \\
\hline & Milk & -0.07 & {$[-0.99]$} & -0.08 & {$[-1.22]$} & -0.06 & {$[-0.96]$} & -0.03 & {$[-0.52]$} & -0.03 & {$[-0.47]$} & -0.04 & {$[-0.56]$} \\
\hline & Butter & -0.15 & {$[-1.33]$} & -0.09 & {$[-0.96]$} & 0.10 & {$[0.87]$} & -0.02 & {$[-0.19]$} & -0.00 & {$[-0.04]$} & -0.03 & {$[-0.32]$} \\
\hline \multirow[t]{6}{*}{ Softs } & Cotton & -0.02 & {$[-0.41]$} & -0.05 & {$[-0.91]$} & -0.11 & {$[-1.97]$} & -0.04 & {$[-0.75]$} & -0.05 & {$[-0.92]$} & -0.08 & {$[-1.67]$} \\
\hline & Cocao & 0.05 & {$[0.87]$} & 0.07 & {$[1.30]$} & 0.02 & {$[0.36]$} & 0.04 & {$[0.68]$} & 0.07 & {$[1.45]$} & -0.02 & {$[-0.32]$} \\
\hline & Sugar & 0.02 & {$[0.40]$} & -0.02 & {$[-0.27]$} & 0.00 & {$[0.00]$} & 0.01 & {$[0.25]$} & -0.08 & {$[-1.53]$} & 0.01 & {$[0.20]$} \\
\hline & Orange Juice & -0.03 & {$[-0.43]$} & 0.01 & {$[0.09]$} & -0.07 & {$[-1.18]$} & -0.00 & {$[-0.06]$} & -0.00 & {$[-0.10]$} & -0.04 & {$[-0.74]$} \\
\hline & Lumber & -0.07 & {$[-1.27]$} & -0.10 & {$[-1.81]$} & -0.04 & {$[-0.71]$} & -0.12 & {$[-2.15]$} & -0.05 & {$[-0.92]$} & -0.02 & {$[-0.37]$} \\
\hline & Coffee & -0.03 & {$[-0.57]$} & -0.15 & {$[-2.71]$} & 0.01 & {$[0.11]$} & -0.18 & {$[-3.36]$} & 0.02 & [0.49] & -0.08 & {$[-1.69]$} \\
\hline
\end{tabular}




\section{References}

Akram, Q. F. (2009). Commodity prices, interest rates and the dollar. Energy Economics, $31(6), 838-851$.

Amihud, Y. (2002). Illiquidity and stock returns: Cross-section and time-series effects. Journal of Financial Markets, 5(1), 31-56.

Barndorff-Nielsen, O. E., \& Shephard, N. (2006). Econometrics of testing for jumps in financial economics using bipower variation. Journal of Financial Econometrics, 4(1), $1-30$.

Barro, R. J. (2006). Rare disasters and asset markets in the twentieth century. Quarterly Journal of Economics, 121(3), 823-866.

Baur, D. G., \& Lucey, B. M. (2010). Is gold a hedge or a safe haven? An analysis of stocks, bonds and gold. Financial Review, 45(2), 217-229.

Baur, D. G., \& McDermott, T. K. (2010). Is gold a safe haven? International evidence. Journal of Banking \& Finance, 34(8), 1886-1898.

Bhardwaj, G., Gorton, G., \& Rouwenhorst, G. (2015). Facts and fantasies about commodity futures ten years later. Working Paper, National Bureau of Economic Research.

Brennan, M. J., \& Schwartz, E. S. (1985). Evaluating natural resource investments. Journal of Business, 58(2), 135-157.

Brooks, C., \& Prokopczuk, M. (2013). The dynamics of commodity prices. Quantitative Finance, 13(4), 527-542. 
Casassus, J., \& Collin-Dufresne, P. (2005). Stochastic convenience yield implied from commodity futures and interest rates. Journal of Finance, 60(5), 2283-2331.

Chatrath, A., \& Song, F. (1999). Futures commitments and commodity price jumps. Financial Review, 34(3), 95-111.

Chevallier, J., \& Ielpo, F. (2014). Twenty years of jumps in commodity markets. International Review of Applied Economics, 28(1), 64-82.

Chong, J., \& Miffre, J. (2010). Conditional correlation and volatility in commodity futures and traditional asset markets. Journal of Alternative Investments, 12(13), 061-075.

Deaton, A., \& Laroque, G. (1992). On the behaviour of commodity prices. Review of Economic Studies, 59(1), 1-23.

Deb, P., Trivedi, P. K., \& Varangis, P. (1996). The excess co-movement of commodity prices reconsidered. Journal of Applied Econometrics, 11 (3), 275-291.

Deng, S. (2000). Pricing electricity derivatives under alternative stochastic spot price models. Proceedings of the 33rd Annual Hawaii International Conference System Sciences, IEEE Computer Society, Washington, D.C..

Diewald, L., Prokopczuk, M., \& Wese Simen, C. (2015). Time-variations in commodity price jumps. Journal of Empirical Finance, 31, 72-84.

Gibson, R., \& Schwartz, E. S. (1990). Stochastic convenience yield and the pricing of oil contingent claims. Journal of Finance, 45(3), 959-976.

Gorton, G., \& Rouwenhorst, K. G. (2006). Facts and fantasies about commodity futures. Financial Analysts Journal, 62(2), 47-68. 
Gorton, G. B., Hayashi, F., \& Rouwenhorst, K. G. (2013). The fundamentals of commodity futures returns. Review of Finance, 17(1), 35-105.

Hilliard, J. E., \& Reis, J. A. (1999). Jump processes in commodity futures prices and options pricing. American Journal of Agricultural Economics, 81(2), 273-286.

Jacod, J., \& Todorov, V. (2009). Testing for common arrivals of jumps for discretely observed multidimensional processes. The Annals of Statistics, 37(4), 1792-1838.

Jiang, G. J., Lo, I., \& Verdelhan, A. (2011). Information shocks, liquidity shocks, jumps, and price discovery: Evidence from the US treasury market. Journal of Financial and Quantitative Analysis, 46(2), 527-551.

Jiang, G. J., \& Oomen, R. C. (2008). Testing for jumps when asset prices are observed with noise-a "swap variance" approach. Journal of Econometrics, 144(2), 352-370.

Jiang, G. J., \& Yao, T. (2013). Stock price jumps and cross-sectional return predictability. Journal of Financial and Quantitative Analysis, 48(5), 1519-1544.

Laurent, S., Lecourt, C., \& Palm, F. C. (2011). Testing for jumps in GARCH models, a robust approach. Working Paper.

Lee, S. S., \& Mykland, P. A. (2008). Jumps in financial markets: A new nonparametric test and jump dynamics. Review of Financial Studies, 21 (6), 2535-2563.

Lombardi, M. J., \& Ravazzolo, F. (2016). On the correlation between commodity and equity returns: Implications for portfolio allocation. Journal of Commodity Markets, $2(1), 45-57$.

Malliaris, A., \& Urrutia, J. L. (1996). Linkages between agricultural commodity futures contracts. Journal of Futures Markets, 16(5), 595-609. 
Manoliu, M., \& Tompaidis, S. (2002). Energy futures prices: Term structure models with Kalman filter estimation. Applied Mathematical Finance, 9(1), 21-43.

Marshall, B. R., Nguyen, N. H., \& Visaltanachoti, N. (2012). Commodity liquidity measurement and transaction costs. Review of Financial Studies, 25(2), 599-638.

Marshall, B. R., Nguyen, N. H., \& Visaltanachoti, N. (2013). Liquidity commonality in commodities. Journal of Banking \& Finance, 37(1), 11-20.

Ohashi, K., \& Okimoto, T. (2016). Increasing trends in the excess comovement of commodity prices. Journal of Commodity Markets, 1(1), 48-64.

Palaskas, T. B., \& Varangis, P. N. (1991). Is there excess co-movement of primary commodity prices?: A co-integration test. Working paper series No. 758, International: Economics Department. World Bank, Washington.

Pindyck, R. (2001). The dynamics of commodity spot and futures markets: A primer. Energy Journal, 22(3), 1-29.

Pindyck, R. S., \& Rotemberg, J. J. (1993). The comovement of stock prices. Quarterly Journal of Economics, $108(4), 1073-1104$.

Prokopczuk, M., Symeonidis, L., \& Wese Simen, C. (2016). Do jumps matter for volatility forecasting? Evidence from energy markets. Journal of Futures Markets, 36(8), 758792.

Pukthuanthong, K., \& Roll, R. (2015). Internationally correlated jumps. Review of Asset Pricing Studies, 5(1), 92-111.

Reboredo, J. C., Rivera-Castro, M. A., \& Zebende, G. F. (2014). Oil and US dollar 
exchange rate dependence: A detrended cross-correlation approach. Energy Economics, 42(2), 132-139.

Rietz, T. A. (1988). The equity risk premium a solution. Journal of Monetary Economics, 22(1), 117-131.

Schwartz, E., \& Smith, J. E. (2000). Short-term variations and long-term dynamics in commodity prices. Management Science, 46(7), 893-911.

Schwartz, E. S. (1997). The stochastic behavior of commodity prices: Implications for valuation and hedging. Journal of Finance, 52(3), 923-973.

Sévi, B. (2015). Explaining the convenience yield in the WTI crude oil market using realized volatility and jumps. Economic Modelling, 44, 243-251.

Silvennoinen, A., \& Thorp, S. (2013). Financialization, crisis and commodity correlation dynamics. Journal of International Financial Markets, Institutions and Money, 24, $42-65$.

Szymanowska, M., Roon, F., Nijman, T., \& Goorbergh, R. (2014). An anatomy of commodity futures risk premia. Journal of Finance, 69(1), 453-482.

Tang, K., \& Xiong, W. (2012). Index investment and the financialization of commodities. Financial Analysts Journal, 68(5), 54-74.

Tauchen, G., \& Zhou, H. (2011). Realized jumps on financial markets and predicting credit spreads. Journal of Econometrics, 160(1), 102-118. 